\section{An adult patient with suspected of monkeypox infection differential diagnosed to chickenpox}

\author{
Junis Tumewu ${ }^{1,5}$ Maya Wardiana, ${ }^{2,3}$ Evy \\ Ervianty, ${ }^{2,3}$ Sawitri, ${ }^{2,3}$ Rahmadewi, ${ }^{2,3}$ \\ Astindari, 2,3 Sylvia Anggraeni, 2,3 \\ Yuri Widia, ${ }^{2,3}$ Mochamad Amin, ${ }^{4}$ \\ Siti Rochmanah Oktaviani Sulichah, ${ }^{1,3}$ \\ K. Kuntaman, ${ }^{1,3,4}$ Juniastuti, ${ }^{1,4}$ \\ Maria Inge Lusida ${ }^{1,3,4}$ \\ ${ }^{1}$ Department of Clinical Microbiology, \\ ${ }^{2}$ Department of Dermatology and \\ Venereology, Faculty of Medicine \\ Universitas Airlangga, Surabaya; \\ ${ }^{3}$ Dr. Soetomo Academic Hospital \\ Surabaya; ${ }^{4}$ Institute of Tropical Disease, \\ Universitas Airlangga, Surabaya; ${ }^{5}$ Naval \\ Medical Department, National Armed \\ Forces, Indonesia
}

\begin{abstract}
Background: Monkeypox is a zoonosis. The disease has a similar appearance to chickenpox caused by the varicella-zoster virus (VZV). On May $9^{\text {th }}$ 2019, there was one laboratory-confirmed case of monkeypox reported in Singapore. A man was also suspected of having monkeypox on June $1^{\text {st }} 2019$ in Surabaya, Indonesia, a neighboring country.
\end{abstract}

Objective: To report on a suspected case of monkeypox with differential diagnosis to chickenpox.

Case: A 51-year-old male was suspected of having monkeypox after a differential diagnosis of chickenpox. His chief complaint was multiple blisters on his body. From the dermatological status on his facial, trunk and extremity regions, there were multiple pleiomorphic vesicles, some with umbilication, with a centripetal distribution, and crusts.

Methods and Results: A PCR using VZV specific primers, followed by genome sequencing showed homologies of more than $99 \%$ to other VZVs and less than 50\% to Monkeypox sequences.

Conclusion: Molecular laboratory techniques have confirmed the case as chickenpox.

\section{Introduction}

Monkeypox is a rare zoonotic disease caused by the monkeypox virus which belong to Orthopoxvirus genus in the fami- ly of Poxviridae. ${ }^{1,2}$ It is transmitted when a person comes into contact with virus from an animal, a human, or any material contaminated with the disease. The virus enters the body through broken skin (even if not visible), the respiratory tract, or the mucous membranes (eyes, nose, or mouth). Animalto-human transmission may occur by bites or scratches, bush meat preparation, direct contact with body fluids or lesion material, or indirect contact with lesion material, such as through contaminated bedding. ${ }^{1}$ The first human case of monkeypox was recorded in 1970 in the Democratic Republic of Congo during a period of intensified effort to eliminate smallpox. ${ }^{1}$ An outbreak happened in the USA in 2003 when the Centers for Disease Control and Prevention (CDC) received reports of patients with a febrile rash illness who had close contact with pet prairie dogs and other animals. $^{3}$ Of the 87 monkeypox cases, 20 (23\%) were laboratory confirmed at the CDC. ${ }^{4}$ In 2017-2018 a monkeypox outbreak happened in Nigeria. ${ }^{5}$ While in May 2019, the Ministry of Health in Singapore notified the WHO of one laboratory-confirmed case of monkeypox. The case-patient was a 38 years old Nigerian man who arrived in Singapore on $28^{\text {th }}$ April 2019. Prior to his travel to Singapore, he had worked in Nigeria in the Delta state, and had attended a wedding on $21^{\text {st }}$ April 2019 in a village in Ebonyi State. The patient developed fever, muscle aches, chills and a skin rash on $30^{\text {th }}$ April. The patient reported that he had remained in his hotel room most of the time between $1^{\text {st }}$ and $7^{\text {th }}$ May. He was transferred to a public hospital by ambulance on $7^{\text {th }}$ May and referred to the National Centre for Infectious Diseases (NCID) on the same day, where he was isolated for further management. Skin lesion samples were taken on $8^{\text {th }}$ May and showed positive for monkeypox virus by the National Public Health Laboratory on the same day. ${ }^{6}$ The Complications of monkeypox include secondary bacterial infections, respiratory distress, bronchopneumonia, gastrointestinal involvement, dehydration, sepsis, encephalitis, and corneal infections with ensuing loss of vision. ${ }^{2}$ The case fatality rate for Monkeypox is $10 \%$, lying between the case fatality rate of variola (or smallpox) major $(30 \%)$ and variola minor $(1 \%){ }^{2}$

Chickenpox caused by VZV has become the primary differential diagnosis because it has a similar clinical appearance. $^{2,7}$ It is distributed worldwide, but it seems that temperate and tropical climates are also affect age-specific incidences. ${ }^{8}$ It is typically seen in children from 1 to 9 years of age. Primary infection in adults is usually more severe. ${ }^{9}$ A study in
Correspondence: Maria Inge Lusida, Institute of Tropical Disease, Universitas Airlangga, Campus C Jalan Mulyorejo, Surabaya, East Java 60115, Indonesia.

Tel. +628124423248

E-mail: ingelusida@itd.unair.ac.id

Key words: monkeypox, chickenpox, adult, Indonesia.

Contribution: All authors contributed equally.

Conflict of interest: the authors declare no potential conflict of interest.

Funding: None.

Acknowledgements: The authors acknowledge Division of Clinical Virology, Center for Infectious Diseases, Kobe University Graduate School of Medicine, Kobe, Japan for kindly giving us the primers and positive control.

Conference presentation: Part of this paper was presented at Infectious Diseases, Biothreats, and Military Medicine (INSBIOMM), 2019 August 27-28, Surabaya, East Java, Indonesia.

Received for publication: 17 February 2020. Accepted for publication: 1 July 2020.

This work is licensed under a Creative Commons Attribution-NonCommercial 4.0 International License (CC BY-NC 4.0).

(C) Copyright: the Author(s), 2020

Licensee PAGEPress, Italy

Infectious Disease Reports 2020; 12(s1):8724 doi:10.4081/idr.2020.8724

the Democratic Republic of Congo (formerly Zaire) showed that among 730 patients diagnosed as cases of chickenpox, 3.3\% had monkeypox by laboratory diagnostic testing and amongst these $7.3 \%$ were diagnosed as "atypical chickenpox". ${ }^{10}$ Laboratory confirmation of infection is critical, because human monkeypox closely resembles several other febrile rash illnesses including smallpox and chickenpox. ${ }^{11}$

\section{Case Report}

On June $1^{\text {st }} 2019$, a 51-year-old male patient was referred from a private hospital to Dr. Soetomo General Academic Hospital, a tertiary referral hospital in Surabaya, Indonesia, with blisters on almost all of his body that worsened in the previous three days. He complained about fever and sore muscles one week before. Three days after that, blisters appeared on his head and then 
spread to his back, chest, and upper arms. This was accompanied by an itchy sensation. The patient had a contact history of feeding a monkey that belonged to the patient's neighbour, but the owner of the monkey did not have any symptoms or abnormalities. A history of travelling prior to these complaints was denied. A history of chickenpox or vaccination before was also denied. Two weeks before, the patient's son was diagnosed with chickenpox.

From a physical examination, his general condition appeared to be sick. The temperature was $36.6^{\circ} \mathrm{C}$. There was no lymph node enlargement on the cervical, axillar, or inguinal regions. From the dermatological status (Figure 1), on the facial region, there were multiple pleiomorphic vesicles (multiple stages of development) and multiple crusts. On the trunk, extremities (superior and inferior regions), there were multiple pleiomorphic vesicles (multiple stages of development), some of them with umbilication and centripetal distribution. A Laboratory examination revealed a hemoglobin level at $12.5 \mathrm{~g} / \mathrm{dL}$, a leucocytes level at $6,870 / \mathrm{uL}$, with a neutrophils level at $65.4 \%$. Vesicle fluid was collected for PCR amplification with specific primers for VZV. Patient sample DNA was extracted using Qiagen. The extracted DNA was used as a template for the amplification of the respective Open Reading Frame (ORF) 14.

PCRs were performed with the PCR master mix (Promega, GoTaq Green Master Mix), $200 \mu \mathrm{L}$ primers for VZV detection (10 picomoles/microliter) and $20 \mu \mathrm{L}$ positive control (Herpesvirus genome 45 $\mathrm{ng} / \mathrm{mL})$. The thermocycling condition included a 5-min denaturation step of $94^{\circ} \mathrm{C}$, followed by 40 cycles of $30 \mathrm{sec}$ at $94^{\circ} \mathrm{C}, 30$ $\mathrm{sec}$ at $53^{\circ} \mathrm{C}$, and $45 \mathrm{sec}$ at $72^{\circ} \mathrm{C}$. ORF 14 was amplified using primers VZV R2 FW (5'-CGGTAAATCTGGCATGCG-3') and VZV R2 Rv (5'- AAGGG GAGCGTGGATGTGTC-3'). Nucleotide sequences of the amplified fragments were determined using the BigDye Deoxy Terminator cycle sequencing kit with an AB 3500XL Genetic Analyzer (Applied Biosystems, Foster City, CA). The result was positive and matching

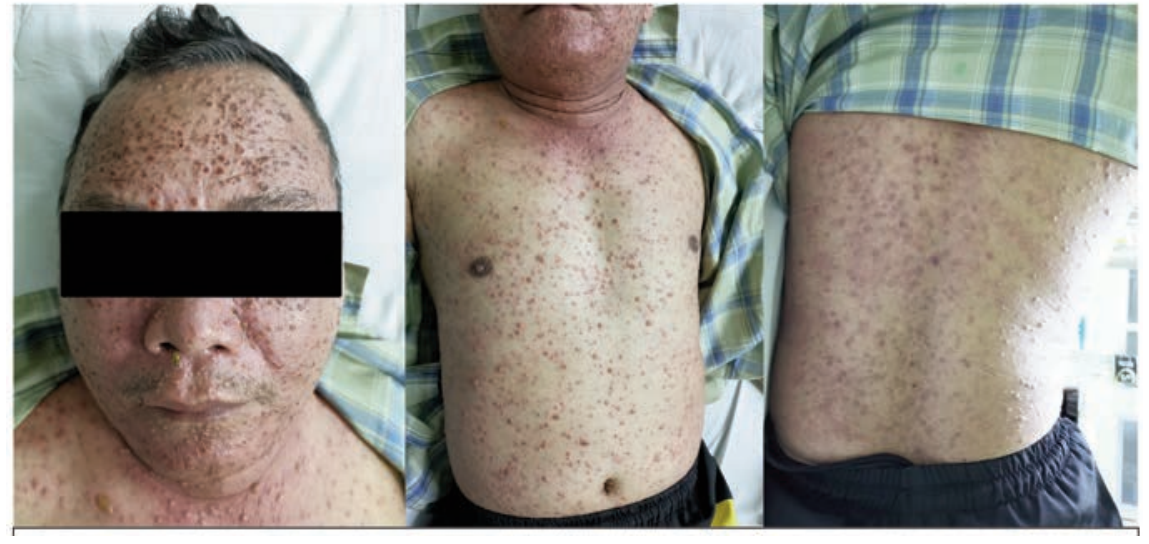

Figure 1. On the facial region, there were multiple pleiomorphic vesicles and multiple crusts. On the trunk, extremities (superior and inferior regions), there were multiple pleiomorphic vesicles. Some of them with umbilication and centripetal distribution.

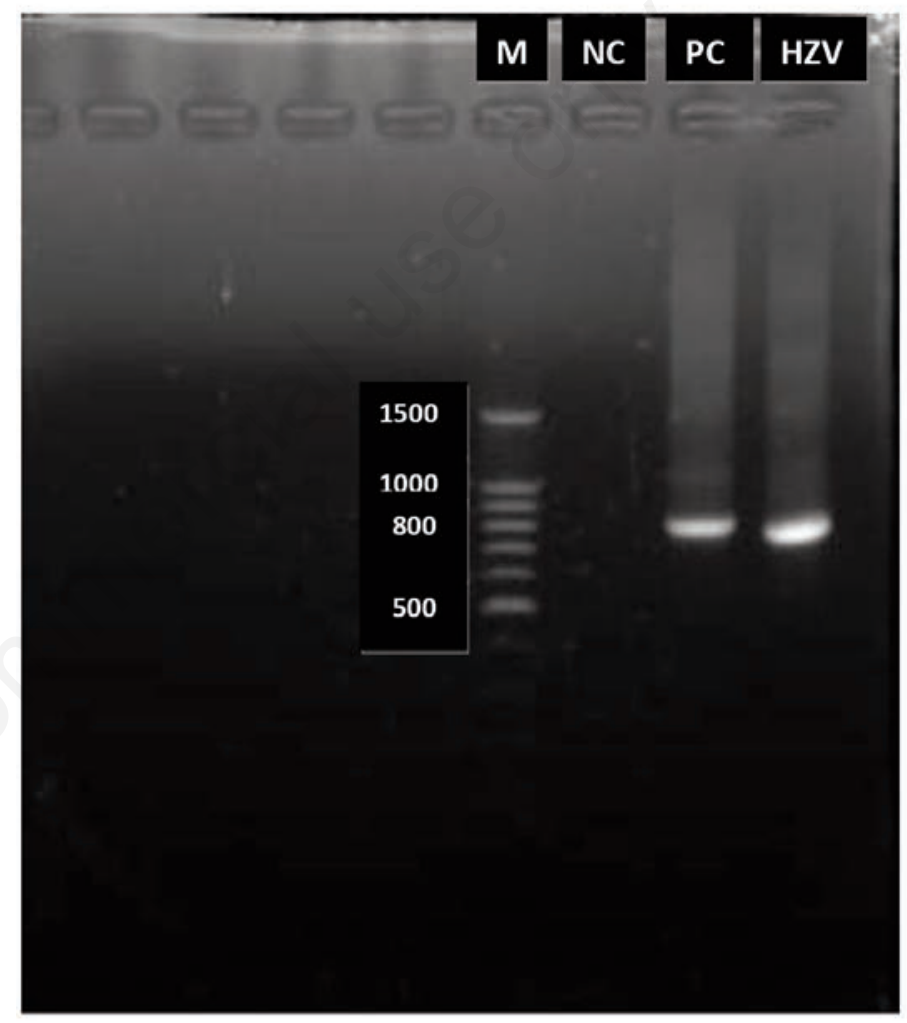

Figure 2. This electrophoresis shows amplicon if $810 \mathrm{bp}$. M: marker (100 BP DNA ladder); NC: negative control; PC: positive control; HZV, patient sample DNA.

Table 1. Nucleotide sequence homology of the patient to other viruses from the GenBank database.

\begin{tabular}{|c|c|c|}
\hline Patient Nucleotide Sequence (813 bp) & Reported isolates from the GenBank & Percentage homology, \% \\
\hline \multirow[t]{6}{*}{ Sby-1.gnu 813} & KM355703.1 * & 99.385 \\
\hline & MH709324* & 99.262 \\
\hline & KJ642616.1 ** & 46.885 \\
\hline & NC_003310.1** & 46.885 \\
\hline & $\mathrm{AY} 243312 * * *$ & 45.395 \\
\hline & KC813493 **** & 44.737 \\
\hline
\end{tabular}

* Sequences of VZV, ${ }^{* *}$ of Monkeypox, ${ }^{* * *}$ of Vaccinia, and ${ }^{* * * *}$ of Cowpox Viruses, indicated by the accession numbers. 
with positive control in the range of $810 \mathrm{bp}$ (Figure 2). It is confirmed at more than $98 \%$ sequence homology to several published VZVs from the GenBank. The patient treated with acyclovir. After 10 days of treatment, all the skin lesions became crusted and the patient was discharged. A written informed consent was obtained.

\section{Discussion}

Monkeypox presents challenges for public health officials and healthcare personnel in terms of surveillance and laboratory capacities, and management and treatment of disease. On May $9^{\text {th }} 2019$, there was one laboratory-confirmed case of monkeypox reported in Singapore. ${ }^{6}$ This situation causes an awareness of the outbreak of monkeypox in Indonesia considering that Singapore is located near to Indonesia and the mobility of travelers between these countries is high. However, the authority had warned that patients with suspected monkeypox should be provided with more careful and accurate laboratory examinations to establish a diagnosis. The patient suspected with monkeypox had been admitted to Dr. Soetomo General Academic Hospital. Outbreak investigations commenced immediately: isolation of the suspected case-patient, a laboratory examination, and contact tracing were conducted. A PCR examination, followed by genome sequencing, was completed. PCR has a very high sensitivity and specificity, ready availability, and a relatively quick (one day or less) turnaround time. For detection of $\mathrm{VZV}$, vesicle fluid is the best specimen for PCR analysis, but lesion scrapings, crusts, tissue biopsy, or cerebrospinal fluid are equally useful. ${ }^{9}$ In this case, a VZV pair primer was used and the result from the patient's sample showed that the amplicon matched with the positive control in the range of $810 \mathrm{bp}$ (Figure 2). It was followed by genome sequencing and the results obtained were compared with reported Nucleotide Sequence Data from the Genbank $^{12}$. From several nucleotide sequences that were compared, results showed high homology to KM355703.1HHV3-Bandim as much as $99.38 \%$ and to MH709324-HHV3-USA as much as $99.26 \%$. Both of them are VZV strains. Whereas the homology to KJ642616.1Monkeypox-Liberia nucleotides was only 46.88\%, and to NC_003310.1-MonkeyPox nucleotides was as low as $46.88 \%$ (Table 1).

Based on this data, the possibility of monkeypox infection in this patient could be ruled out and the diagnosis of chickenpox could be established.

\section{Conclusions}

A VZV of an adult case in Surabaya, Indonesia, which was clinically similar to a more pathogenic Monkeypox, was confirmed by a molecular diagnostic laboratory test. We are relieved, since a confirmed monkeypox was recently found in an African citizen who came into Singapore, a neighbouring country.

\section{References}

1. Centers for Disease Control and Prevention. Monkeypox | Poxvirus | CDC; 2019. Available from: https://www.cdc.gov/poxvirus/monkeypox/index.html. Accessed: August 2019

2. Sklenovská N, Van Ranst M. Emergence of monkeypox as the most important orthopoxvirus infection in humans. Front Public Heal 2018;6:24152.

3. Centers for Disease Control and Prevention. Multistate Outbreak of Monkeypox - Illinois, Indiana, and Wisconsin, 2003. MMWR Morb Mortal
Wkly Rep 2003;52:537-40.

4. Centers for Disease Control and Prevention. Update: Multistate Outbreak of Monkeypox - Illinois, Indiana, Kansas, Missouri, Ohio, and Wisconsin, 2003. MMWR Morb Mortal Wkly Rep 2003;52:561-4.

5. Yinka-Ogunleye A, Aruna O, Dalhat M, Ogoina D, McCollum A, Disu Y, et al. Outbreak of human monkeypox in Nigeria in 2017-18: a clinical and epidemiological report. Lancet Infect Dis 2019;19:872-9.

6. World Health Organization. Monkeypox - Singapore. WHO. World Health Organization; 2019 [cited 2019 Jul 28]. Available from: https://www.who.int/csr/don/16-may2019-monkeypox-singapore/en/

7. Giulio DB Di, Eckburg PB. Reviews human monkeypox: an emerging zoonosis. Lancet 2004;4:15-25.

8. Gershon AA, Breuer J, Cohen JI, Cohrs RJ, Michael D, Gilden D, et al. Varicella zoster virus infection. Nat Rev Dis Prim 2015;1:1-41.

9. Levin MJ, Schmader KE, Oxman MN. Varicella and herpes zoster. In: Kang S, Amagai M, Bruckner AL, Enk AH, Margolis DJ, McMichael AJ, et al., editors. Fitzpatrick's Dermatology. 9th ed. New York: McGraw-Hill Education; 2019. pp. 3035-64.

10. Jezek Z, Szczeniowski M, Paluku KM, Mutombo M, Grab B. Human monkeypox: confusion with chickenpox. Acta Trop 1988 Dec;45:297-307.

11. Durski KN, McCollum AM, Nakazawa Y, Petersen BW, Reynolds MG, Briand $\mathrm{S}$, et al. Emergence of Monkeypox West and Central Africa, 1970-2017. Morb Mortal Wkly Rep 2018;67:30610 .

12. Benson DA, Cavanaugh M, Clark K, Karsch-Mizrachi I, Lipman DJ, Ostell J, et al. GenBank. Nucleic Acids Res 2013;41:36-42. 